
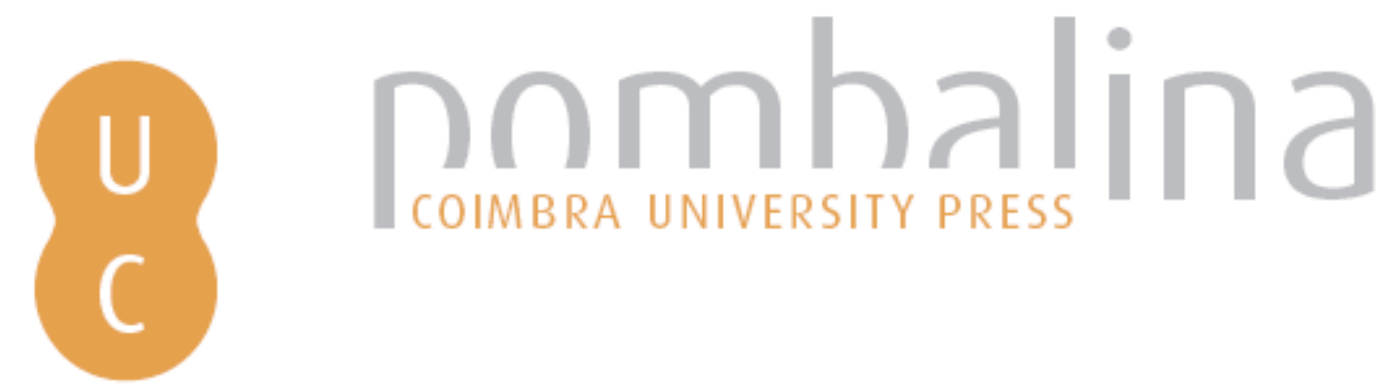

\title{
Modelação em sistemas de informação geográfica da avaliação da susceptibilidade a movimentos de vertente na área amostra de Lousa-Loures (Região a norte de Lisboa)
}

\begin{tabular}{|c|c|}
\hline Autor(es): & $\begin{array}{l}\text { Piedade, Aldina; Zêzere, José Luís; Tenedório, José António; Garcia, } \\
\text { Ricardo A. C.; Oliveira, Sérgio Cruz de; Rocha, Jorge }\end{array}$ \\
\hline Publicado por: & Imprensa da Universidade de Coimbra \\
\hline $\begin{array}{l}\text { URL } \\
\text { persistente: }\end{array}$ & URI:http://hdl.handle.net/10316.2/30997 \\
\hline DOl: & DOI:http://dx.doi.org/10.14195/978-989-26-0244-8_60 \\
\hline Accessed : & 26-Apr-2023 14:48:48 \\
\hline
\end{tabular}

A navegação consulta e descarregamento dos títulos inseridos nas Bibliotecas Digitais UC Digitalis, UC Pombalina e UC Impactum, pressupõem a aceitação plena e sem reservas dos Termos e Condições de Uso destas Bibliotecas Digitais, disponíveis em https://digitalis.uc.pt/pt-pt/termos.

Conforme exposto nos referidos Termos e Condições de Uso, o descarregamento de títulos de acesso restrito requer uma licença válida de autorização devendo o utilizador aceder ao(s) documento(s) a partir de um endereço de IP da instituição detentora da supramencionada licença.

Ao utilizador é apenas permitido o descarregamento para uso pessoal, pelo que o emprego do(s) título(s) descarregado(s) para outro fim, designadamente comercial, carece de autorização do respetivo autor ou editor da obra.

Na medida em que todas as obras da UC Digitalis se encontram protegidas pelo Código do Direito de Autor e Direitos Conexos e demais legislação aplicável, toda a cópia, parcial ou total, deste documento, nos casos em que é legalmente admitida, deverá conter ou fazer-se acompanhar por este aviso.

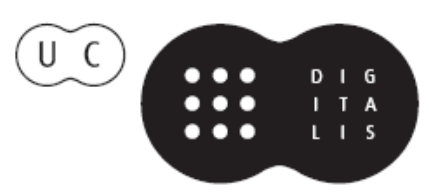




\section{TRUNFOS DE UMA}

\section{EOGRAFIA ACIVA}

\section{DESENVOLVIMENTO LOCAL,}

AMBIENTE,

ORDENAMENTO

E TECNOLOGIA

Norberto Santos

Lúcio Cunha

COORDENAÇÃO 
Aldina Piedade ${ }^{1}$, José Luís Zêzere ${ }^{1}$, José António Tenedório ${ }^{2}$, Ricardo A. C. Garcia ${ }^{1}$, Sérgio Cruz de Oliveira ${ }^{1}$, Jorge Rocha ${ }^{1}$

${ }^{1}$ Centro de Estudos Geográficos. Instituto de Geografia e Ordenamento do Território. Universidade de Lisboa

2 e-Geo. Faculdade de Ciências Sociais e Humanas. Universidade Nova de Lisboa

\author{
MODELAÇÃO EM SISTEMAS DE INFORMAÇÃO GEOGRÁFICA DA AVALIAÇÃO DA \\ SUSCEPTIBILIDADE A MOVIMENTOS DE VERTENTE NA ÁREA AMOSTRA DE LOUSA-LOURES \\ (REGIĀO A NORTE DE LISBOA)
}

\title{
1. INTRODUÇÃO
}

A avaliação da susceptibilidade a movimentos de vertente baseia-se no princípio de que os factores que condicionaram a actividade de deslizamentos no passado e presente serão igualmente responsáveis pela ocorrência dos futuros episódios de instabilidade geomorfológica. A metodologia utilizada neste trabalho teve por base duas questóes de partida: i) sendo conhecida a variação espacial da susceptibilidade de uma área é viável a aplicação directa dos scores de susceptibilidade correspondentes em áreas que apresentem características geológicas e geomorfológicas similares? ii) qual é o grau de erro introduzido por esta abordagem em comparação com a avaliação de susceptibilidade mais habitual, baseada na exploração do inventário de movimentos de vertente da área teste?

A aplicação e validação de um modelo de susceptibilidade na área de Lousa-Loures (área teste) com recurso a algoritmos obtidos para a área de Fanhóes-Trancão (área modelo), justificase pelo facto destas áreas terem características geológicas e geomorfológicas similares e pela existência da mesma tipologia de deslizamentos, nomeadamente os deslizamentos translacionais superficiais. Paralelamente, é desenvolvida a avaliação da susceptibilidade na área de LousaLoures, com recurso ao inventário de deslizamentos translacionais superficiais dessa área. Foram criadas e utilizadas bases de dados relacionais que transcrevem as relaçóes entre os factores de predisposição da instabilidade e os deslizamentos translacionais superficiais, com recurso à modelação através de Sistemas de Informação Geográfica (SIG). Para possibilitar as comparaçóes, procedeu-se à homogeneização dos dados de partida nas duas áreas e utilizou-se uma única ferramenta estatística para avaliar a susceptibilidade: o Método do Valor Informativo. Os resultados obtidos são validados através de técnicas estandardizadas, descritas na literatura especializada (e.g. Chung e Fabbri, 2003; Guzzetti, 2005) e já aplicados em estudos similares na regiáo a norte de Lisboa (e.g. Reis et al., 2003; Zêzere et al., 2004).

\section{CARACTERIZAÇÃo DA ÁREA DE ESTUDO}

A área teste de Lousa-Loures abrange uma superfície de $17 \mathrm{~km}^{2}$ e insere-se na regiāo a Norte de Lisboa (Fig. 1). É drenada pelo Rio de Loures e seus afluentes, que se integram na 
bacia hidrográfica do Rio Trancão. Esta área é marcada pela presença de rochas de diferentes dureza, permeabilidade e plasticidade, que, juntamente com uma disposição monoclinal com pendores fracos a moderados $\left(8^{\circ}\right.$ a $\left.30^{\circ}\right)$ para SSE e SE, levou ao desenvolvimento de relevos de costeira (Ferreira, 1984). Do ponto de vista litológico destacam-se os materiais do Complexo Vulcânico de Lisboa ( $47 \%$ da área total) e as rochas sedimentares do Cretácico (calcários, arenitos, calcários margosos, pelitos e dolomitos) (38\% da área total).

Figura 1 - Geologia da região a Norte de Lisboa e localização das áreas de Lousa-Loures e de Fanhóes-Trancão

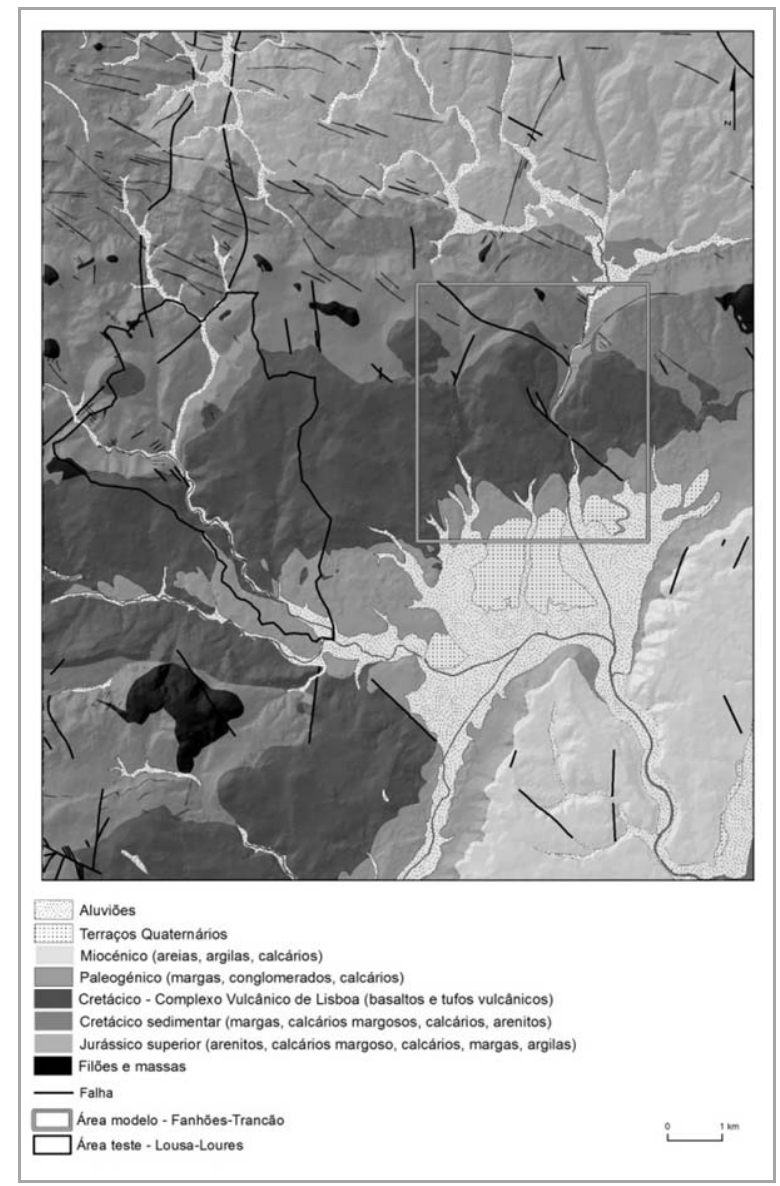

A área modelo de Fanhóes-Trancão insere-se no sector intermédio da bacia hidrográfica do Rio Trancão, sendo também parte integrante da costeira de Lousa-Bucelas (Fig. 1). Localiza-se no reverso deste relevo estrutural, que acompanha a estrutura monoclinal com inclinação de $12^{\circ}$ para S (Zêzere et al., 1999; Reis et al., 2003). A exemplo do verificado na área de Lousa-Loures, do ponto de vista litológico destacam-se os afloramentos do Complexo Vulcânico de Lisboa ( $49 \%$ da área total) e as rochas sedimentares de idade cretácica (calcários, arenitos, calcários margosos) (25\% da área total). 


\section{MOVIMENTOS DE VERTENTE E FACTORES DE PREDISPOSIÇÃO}

Os deslizamentos são o tipo de movimento de vertente analisado neste trabalho. De acordo com a WP/WLI (1993), um deslizamento é um movimento de solo ou rocha que ocorre predominantemente ao longo de planos de ruptura ou de zonas relativamente estreitas, alvo de intensa deformaçáo tangencial. O tipo de ruptura tangencial e as características do material afectado constituem os principais critérios para a subdivisão dos deslizamentos, em rotacionais e translacionais. Adicionalmente, o termo superficial é utilizado quando a deslocação do material não afecta o substrato rochoso, ocorrendo apenas no depósito que regulariza as vertentes e que apresenta uma espessura tipicamente compreendida entre os 0,5 e $2 \mathrm{~m}$. $\mathrm{Na}$ área de estudo os deslizamentos translacionais superficiais estão relacionados, muitas vezes, com a abertura de taludes antrópicos e com a erosão lateral dos cursos de água.

Figura 2 - Distribuição dos deslizamentos translacionais superficiais na área de Lousa-Loures (representados por símbolos adimensionais).

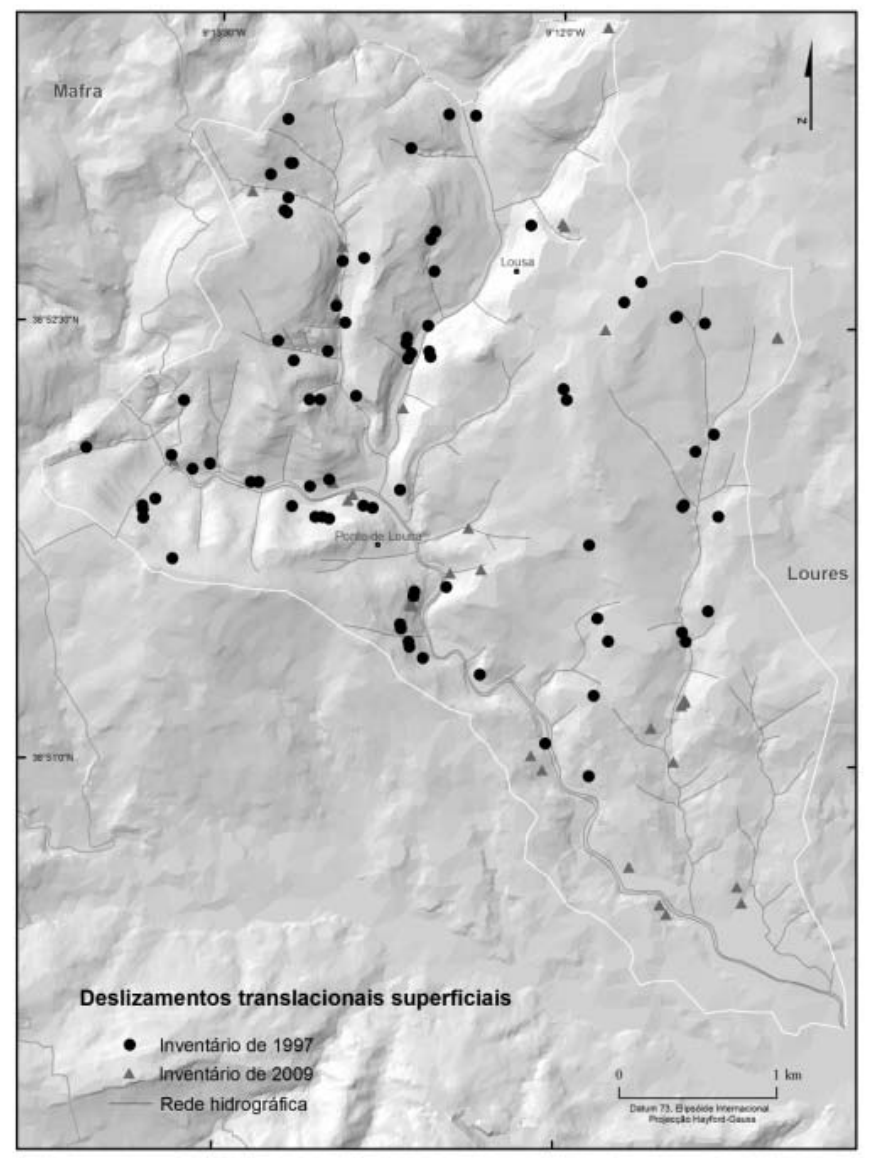


A base de dados dos deslizamentos translacionais superficiais consiste em dois inventários, obtidos através de levantamento de campo (Fig. 2). O primeiro foi efectuado em 1997 (Zêzere, 1997) e integra 82 deslizamentos a que correspondem $37099 \mathrm{~m}^{2}$ de área deslizada. O segundo inventário foi efectuado em 2009 e inclui 36 deslizamentos (ocorridos após 1997), com uma área total instabilizada de $6294 \mathrm{~m}^{2}$.

Os factores de predisposição da instabilidade geomorfológica assumidos como capazes de predizer a distribuiçáo espacial dos deslizamentos e usados na avaliação da susceptibilidade foram seleccionados tendo como referência os estudos já realizados na área modelo de Fanhôes-Trancão (e.g., Reis et al., 2003; Zêzere et al., 2004). Assim, foram considerados o declive, a exposição das vertentes, o perfil transversal das vertentes, as unidades litológicas, os depósitos superficiais, as unidades geomorlógicas e o uso do solo, que constituem as variáveis independentes dos modelos. As classes que ocorrem numa única área não foram consideradas no processo de transferência dos scores de susceptibilidade da área de Fanhóes-Trancão para a área de Lousa-Loures.

\section{METODOLOGIA}

Partiu-se do conhecimento da instabilidade geomorfológica previamente adquirido para a área de Fanhóes-Trancáo para definir a susceptibilidade a deslizamentos translacionais superficiais na área de Lousa-Loures. O pressuposto de partida é que os futuros movimentos de vertente têm maior probabilidade de ocorrer sob condiçóes geológicas e geomorfológicas idênticas às que determinaram a instabilidade presente e passada, bem como, que as mesmas causas são susceptíveis de originar os mesmos efeitos. Neste sentido, a avaliação da susceptibilidade na área teste é efectuada através da importação de scores de susceptibilidade obtidos para a área modelo.

Numa segunda abordagem, a disponibilidade de um inventário dos deslizamentos para a área de Lousa-Loures permitiu o cálculo de índices de susceptibilidade com base nos dados da área teste, com o objectivo de comparar e discutir os resultados.

$\mathrm{Na}$ avaliação da susceptibilidade utilizou-se o método estatístico bivariado do Valor Informativo (Yin e Yan, 1988). Esta técnica descreve quantitativamente, sob a forma de scores, as relaçôes existentes entre cada uma das classes de cada variável e os movimentos de vertente. $\mathrm{O}$ método pressupóe a definição prévia da unidade de terreno (aqui assumida como pixel, com uma resolução de $5 \times 5 \mathrm{~m}$ ) e um conjunto de factores de instabilidade (classes de cada variável), sendo os respectivos Valores Informativos determinados a partir da seguinte equação (Yin e Yan, 1988):

$$
I i=\frac{S i / N i}{S / N}[1]
$$

em que: $I i$ é o Valor Informativo da variável $i$; $S i$ é o número de pixels com movimentos de tipo y e com presença da variável $i$; $N i$ é o número de pixels com a presença da variável $i$; $S$ é o número total de pixels com movimentos de vertente tipo $y$; e $N$ é o número de pixels na área de estudo. 
O Valor Informativo total para cada unidade de terreno é definido pela seguinte expressão:

$$
I j=\sum_{i=1}^{n} X j i . I i
$$

em que: $I i$ é o Valor Informativo do pixel $j$; $n$ é o número de variáveis; $X j i$ corresponde a 0 , se a variável não está presente no pixel $j$, e 1 na situação contrária.

Esta metodologia permite a obtenção de scores de susceptibilidade, mesmo de unidades de terreno que ainda não foram afectados por movimentos. $\mathrm{Na}$ aplicação do método, cada factor de instabilidade é cruzado com a distribuiçáo dos movimentos de vertente, daí resultando os scores para cada classe de cada variável.

A validaçáo dos resultados é sustentada pelo cruzamento dos mapas de susceptibilidade com a distribuição dos deslizamentos translacionais superficiais. O grau de ajuste entre os dados e o modelo é determinado através do cálculo da taxa de sucesso (o mapa de susceptibilidade é cruzado e validado com os movimentos de vertente que lhe deram origem) e a respectiva capacidade preditiva através da taxa de predição (o mapa de susceptibilidade é cruzado e validado com uma amostra de movimentos de vertente independente, não considerada na construção do modelo preditivo). A aferição da capacidade preditiva do modelo de susceptibilidade foi possível através da partição temporal dos dados de instabilidades, sustentada num novo inventário obtido em 2009, e que foi usado para a validação do modelo construído com base nos deslizamentos translacionais superficiais inventariados em 1997. A qualidade global dos mapas de susceptibilidade foi avaliada através do cálculo da Área Abaixo da Curva (AAC), resultante da representação gráfica das taxas de sucesso e predição.

\section{MAPAS DE SUSCEPTIBILIDADE A DESLIZAMENTOS TRANSLACIONAIS SUPERFICIAIS}

A observação dos mapas de susceptibilidade à ocorrência de deslizamentos translacionais superficiais (Fig. 3) permite concluir que estes são bastantes parecidos, sendo que as classes de susceptibilidade mais elevadas localizam-se em áreas com características naturais similares, nomeadamente nas vertentes com declive mais acentuado, nas áreas de anverso de costeira $\mathrm{e}$ na unidade litológica correspondente às margas e calcários margosos. A mancha com maior expressáo territorial corresponde às áreas com menor susceptibilidade à ocorrência de deslizamentos translacionais superficiais, caracterizando-se por vertentes de declives suaves e talhadas em basaltos, tufos vulcânicos, conglomerados e arenitos

O ajuste dos mapas A e B pode ser expresso pela taxa de concordância (\%) das classes de susceptibilidade. Se considerarmos os primeiros $5 \%$ de área classificada como mais susceptível, verificamos que há uma concordância de $43 \%$ entre os dois mapas. Esse valor aumenta para $56 \%$ quando se comparam os $10 \%$ de área classificada como mais propensa à ocorrência de deslizamentos translacionais superficiais. 
Figura 3 - Mapas de susceptibilidade a deslizamentos translacionais superficiais na área de Lousa-Loures

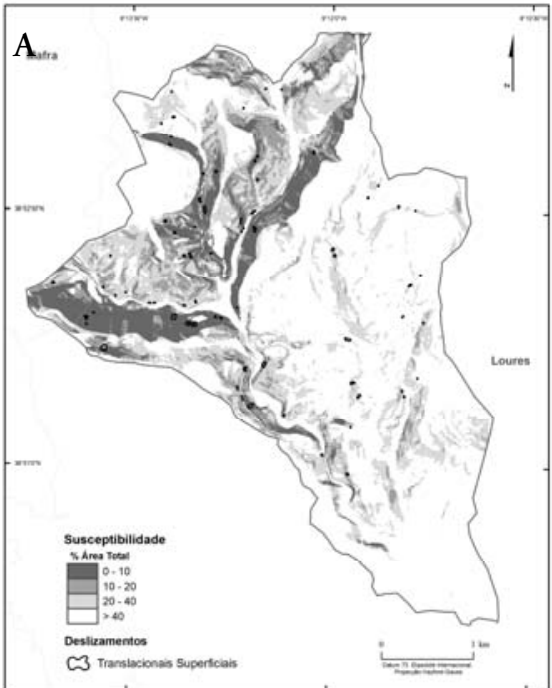

A - VI de Lousa-Loures;

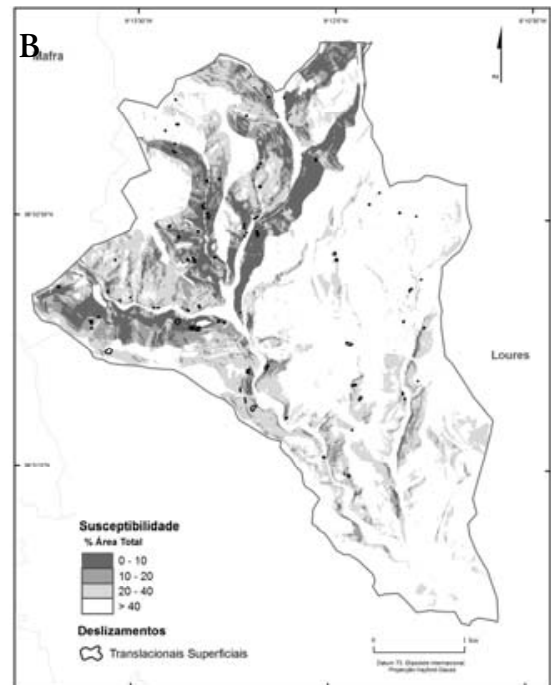

B - VI de Fanhóes-Trancão

\section{VALIDAÇÃO DOS MAPAS DE SUSCEPTIBILIDADE: CURVAS DE SUCESSO E PREDIÇÃO}

A figura 4 apresenta as curvas de sucesso (tracejado) e de predição (cinza claro), e as respectivas Áreas Abaixo da Curva (AAC), respeitantes aos dois modelos de susceptibilidade representados na figura 3. O modelo obtido com os movimentos de Lousa-Loures apresenta uma AAC superior à obtida para a área teste com os Valores Informativos de Fanhóes-Trancáo, (0,839 e 0,779, respectivamente). De acordo com o critério de Guzzetti (2005), estes modelos são classificados como "muito bom" e aceitável", respectivamente. No entanto, estes dados náo sáo directamente comparáveis, uma vez que o primeiro fornece o grau de ajuste dos dados ao modelo e o segundo a capacidade preditiva do mesmo.

Os valores obtidos com a taxa de predição não se distanciam muito dos da curva de sucesso: aos $10 \%$ da área total a validação é de 36\% dos movimentos. Com $50 \%$ da área de estudo são validados $90 \%$ dos deslizamentos translacionais superficiais.

A figura 4 representa ainda as curvas de predição obtidas pela sobreposição dos deslizamentos translacionais inventariados em 2009 na área de Lousa-Loures. Em comparação com a curva de sucesso da área de Lousa-Loures (tracejado) verifica-se que o modelo validado com deslizamentos de 2009 (cinza escuro) fica abaixo da curva de ajuste, como seria expectável tratando-se de uma curva de predição, com AAC de 0,787. O modelo de susceptibilidade produzido com scores de VI importados da área modelo apresenta uma capacidade preditiva dos movimentos inventariados em 2009 ligeiramente superior comparativamente ao anterior, com uma AAC de 0,796. Este facto pode estar relacionado com a sub-dimensão da amostra de deslizamentos translacionais superficiais (36) e com a área deslizada reduzida $\left(6294 \mathrm{~m}^{2}\right)$, que foi utilizada para a validação. Por outro lado, sendo conhecido que o factor de predisposição "declive" tem um papel determinante na ocorrência desta tipologia de 
movimentos, calculou-se o VI para essa variável com os deslizamentos translacionais superficiais do inventário de 2009. Os valores obtidos aproximam-se mais dos observados na área modelo do que os observados na área teste, ou seja, os deslizamentos translacionais superficiais ocorridos na área de Lousa-Loures entre 1997 e 2009 verificaram-se em vertentes com declive mais acentuado, comparativamente ao observado antes de 1997, e mais próximo da situação que caracterizou este tipo de movimentos na área de Fanhóes-Trancão, sendo este o principal motivo da obtenção de melhores AAC.

Figura 4 - Curva de sucesso (tracejado), curvas de predição e respectivas AAC dos modelos de susceptibilidade a deslizamentos translacionais superficiais validados com inventários de 1997 e 2009.

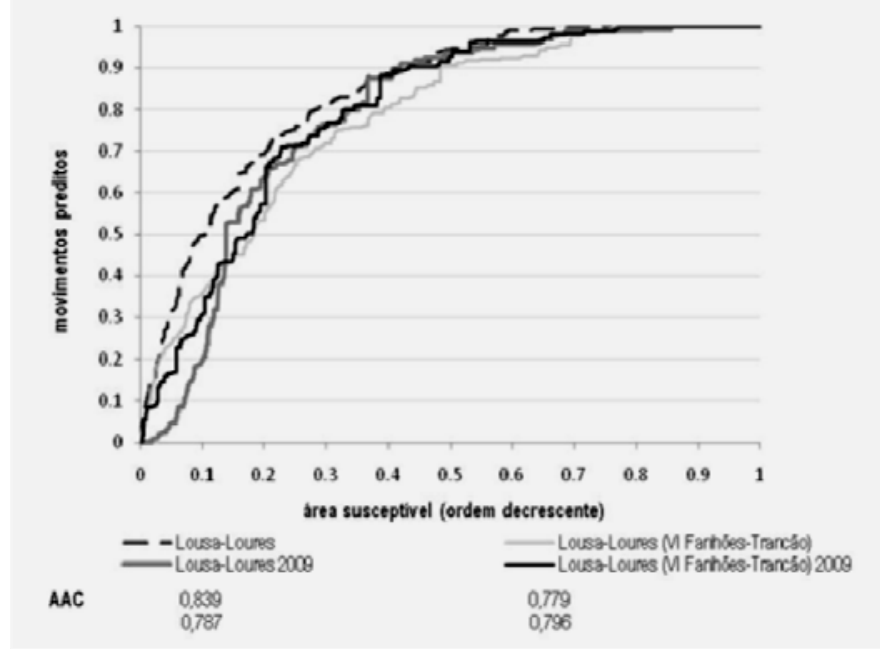

\section{CONSIDERAÇÓES FINAIS}

Os resultados obtidos através da exportação de scores de susceptibilidade para uma área com características geológicas e geomorfológicas similares, com modelação em SIG, mostram que se trata de uma metodologia válida, tratando-se de movimentos de vertente da mesma tipologia. O pressuposto que as mesmas causas são susceptíveis de gerar os mesmos efeitos, num contexto geológico e geomorfológico similar foi validado pela metodologia desenvolvida. Para tal, em muito contribuíram os procedimentos analíticos sustentados por inventários de movimentos de vertente robustos e pela utilizaçáo de um método estatístico simples, mas fiável (Valor Informativo) em ambiente SIG.

Os mapas de susceptibilidade produzidos com scores obtidos nas duas áreas de estudo apresentam um elevado nível de concordância; por exemplo, aos $20 \%$ de área classificada como mais susceptível a sobreposição entre eles é de 76\%.

Os resultados obtidos, para além de confirmarem a viabilidade da aplicação directa de scores de susceptibilidade em áreas que apresentem características geológicas e geomorfológicas similares, revelam ainda que o Método do Valor Informativo constitui uma boa escolha 
para a atribuição objectiva dos pesos das variáveis e para a integração de dados estatísticos na análise e na modelação espacial.

Em resposta à segunda pergunta de partida, observa-se que grau de incerteza associado a esta abordagem metodológica, em comparação com a avaliação de susceptibilidade mais habitual, baseada na exploração de um inventário de deslizamentos da área de estudo, revelou-se baixo; a diferença entre AAC de curva de sucesso e AAC da curva de predição é apenas de 0,06 .

O inventário de movimentos de vertente produzido em 2009 valida os mapas de susceptibilidade, num processo de validação independente de base temporal, confirmando a robustez dos modelos e a sua capacidade para prever a distribuiçáo espacial dos futuros deslizamentos translacionais superficiais.

A metodologia apresentada e respectiva validação constitui um exercício académico de carácter científico. A sua transposição e generalização em Planos de Ordenamento do Território só poderá ser efectuada quando houver disponibilidade de um inventário de instabilidades para a área em estudo que permita validar os mapas de susceptibilidade; só assim se poderá avaliar a capacidade preditiva dos modelos e a sua validação científica. Assim, é desaconselhável a realização de modelos de susceptibilidade nessas circunstâncias, sob pena de se cometerem erros grosseiros que distorcem a realidade, com graves consequências para o ordenamento do território.

Este estudo é parte do Projecto MapRisk (PTDC/GEO/68227/2006) financiado pela Fundação para a Ciência e Tecnologia.

\section{REFERÊNCIAS BIBLIOGRÁFICAS}

Chung, C. J., Fabbri, A. 2003, 'Validation of Spatial Prediction Models for Landslide Hazard Mapping', Natural Hazards, n. ${ }^{\circ}$ 30, pp 451-472.

Ferreira, A. B. 1984, 'Mouvements de terrain dans la Région au Nord de Lisbonne. Conditions morphostructurales et climatiques', Mouvements de Terrain. Colloque de Caen. Documents du B.R.G.M., n. o 83, pp. 485-494.

Guzzetti, F. 2005, Landslide Hazard and Risk Assessment. Dissertação de Doutoramento. Universidade de Bona, $371 \mathrm{pp}$.

Reis, E., Zêzere, J. L., Vieira, G. T., Rodrigues, M. L. 2003, 'Integração de dados espaciais em SIG para a avaliação da susceptibilidade à ocorrência de deslizamentos', Finisterra XXXVIII: 76, pp 3-34.

Varnes, D. J. 1978, 'Slope Movement Types and Processes' In SCHUSTER, R. L., KRIZEK, R. J. (eds.), Landslides, Analysis and Control, Transportation Research Board Special Report, 176. Washington D.C..

Working Party On World Landslide Inventory, Unesco 1993, 'A suggested method for describing the activity of a landslide'. Bulletin of the International Association of Engineering Geology, n. ${ }^{\circ} 47$, pp. 53-57.

Yin, K. L., Yan, T. Z. 1988, Statistical prediction models for slope instability of metamorphosed rocks. Bonnard, (ed.), Landslides. Proceedings of the Fifth International Symposium on Landslides, 2, Balkema, Rotterdam, pp. 1269-1272.

Zêzere, J. L. 1997, Movimentos de Vertente e Perigosidade Geomorfológica na Região a Norte de Lisboa, Dissertação de Doutoramento, Faculdade de Letras da Universidade de Lisboa, Lisboa, 576 pp.

Zêzere, J. L., Ferreira, A. B., Rodrigues, M. L. 1999, 'The role of conditioning and triggering factors in the occurrence of landslides: a case study in the area north of Lisbon (Portugal)', Geomorphology, 1-2 n.o 30, pp. 133-146.

Zêzere, J. L., Reis, E., Garcia, R., Oliveira, S., Rodrigues, M. L., Vieira., Ferreira A. B. 2004, 'Integration of spatial and temporal data for the definition of different landslides hazard scenarios in the area north of Lisbon (Portugal)' Natural Hazard and Earth System Sciences n. ${ }^{\circ} 4$, pp. 133-146. 